Markus Meurer, Berk Tekkaya*, Thorsten Augspurger, Thomas Pullen, Daniel Schraknepper, Thomas Bergs, and Sebastian Münstermann

\title{
Cutting force based surface integrity soft-sensor when hard machining AISI 4140
}

\author{
Zerspankraftbasierter Oberflächenintegritätssoftsensor bei der Hartbearbeitung von AISI \\ 4140
}

https://doi.org/10.1515/teme-2020-0050

Received July 20, 2020; accepted September 10, 2020

\begin{abstract}
Workpiece rim zone modifications during hard machining can be explained with the high thermomechanical loads induced by the cutting process. The formation of White Layers with a fine-grained microstructure by dynamic recrystallization (DRX) is one of those surface modifications that can negatively affect the functionality of a machined part by changing the residual stress state and facilitating crack initiation. As a consequence, the fatigue life of the machined parts is reduced. It is therefore of great interest to understand the thermo-mechanical conditions which induce White Layers formation in order to be able to control them by in-situ measurements if necessary. For this purpose, a cutting force based Soft-Sensor is developed in this study which enables the in-process estimation of White Layer thickness. Therefore, a cutting force based analytical model is used to estimate the resulting temperature fields and correlated with validated numerical chip formation simulations. In addition, the predictions of the White Layer thickness of the analytical model are then compared using light microscopy and the results of the numerical finite element model, in which a DRX model is additionally implemented.
\end{abstract}

Keywords: Surface integrity, soft-sensor, FEM, DRX, cutting.

Zusammenfassung: Modifikationen der Werkstückrandzone während des Hartdrehens sind auf die hohen thermomechanischen Beanspruchungen zurückzuführen, die lokal auf den Werkstoff einwirken. Die Bildung des White Layers mit feinkörniger Mikrostruktur durch dynami-

\footnotetext{
*Corresponding author: Berk Tekkaya, RWTH Aachen University, Integrity of Materials and Structures, Steel Institute (IEHK), Aachen, Germany, e-mail: berk.tekkaya@iehk.rwth-aachen.de

Markus Meurer, Thorsten Augspurger, Thomas Pullen, Daniel Schraknepper, Thomas Bergs, RWTH Aachen University, Laboratory for Machine Tools and Production Engineering (WZL), Aachen, Germany

Sebastian Münstermann, RWTH Aachen University, Integrity of Materials and Structures, Steel Institute (IEHK), Aachen, Germany
}

sche Rekristallisation (DRX) gehört zu diesen Oberflächenmodifikationen. Diese und andere Modifikationen beeinflussen die Funktionalität eines zerspanten Bauteils negativ, indem sie den Eigenspannungszustand verändern und die Rissinitiierung erleichtern. Somit verringert sich die Lebensdauer der gefertigten Bauteile. Aus diesem Grund ist es von großer Bedeutung zu verstehen, bei welchen Schnittbedingungen White Layer entstehen, um diese gegebenenfalls durch In-Prozess-Messungen abschätzen zu können. Daher wurde in dieser Arbeit ein Soft-Sensor entwickelt, der es ermöglicht, die Dicke des White Layer InProzess zu bestimmen. Hierfür wird ein prozesskraftbasiertes analytisches Modell zur Abschätzung der entstehenden Temperaturfelder verwendet und mit validierten numerischen Spanbildungssimulationen korreliert. Außerdem wurden die anschließenden Vorhersagen der White Layer Dicke des Soft-Sensors mit den Ergebnissen des numerischen Finite-Elemente-Modells, in dem zusätzlich ein DRX-Modell implementiert ist und lichtmikroskopisch untersuchten Gefügeproben verglichen.

Schlagwörter: Oberflächenintegrität, Softsensor, FEM, DRX, Drehen.

\section{Introduction}

High thermo-mechanical loads that are generated during the hard turning process have a great influence on the functionality of a machined part [1, 2]. These loads are responsible for microstructural alterations, modification of hardness, residual stress state, mechanical properties, chemical composition and corrosion resistance in the workpiece rim zone [3]. These surface characteristics are collectively known as Surface Integrity [1].

The formation of White Layers in the workpiece rim zone is known to be one of the key aspects of Surface Integrity. They are typically characterized by a very fine grain size due to dynamic recrystallization (DRX), high hardness and a brittle structure compared to the bulk material [4]. 
Due to these modifications in the microstructure, White Layers increase crack initiation and influence the residual stress state, thus adversely affect the part functionality regarding to the fatigue life [5]. Therefore, it is of high interest to understand under which thermomechanical conditions White Layers are formed.

For years, numerous research has been conducted on various frameworks to model workpiece surface alterations based on dynamic recrystallization (DRX). For example, in one of the earlier studies, Yanagimoto et al. used the empirical Zener-Hollomon parameter with an Avrami type kinetics equation to predict the grain size evolution in compression tests [6]. Ambrosy et al. employed this approach to model dynamic recrystallization when cutting AISI 4140 [7]. For the prediction of the hardening behavior at large strains, Estrin et al. presented a dislocation density-based framework [8]. With the interpretation of cell size as grain size the dislocation density-based model is adopted by many researches to simulate dynamic recrystallization when machining different materials such as steels [9, 10], titanium [11] and aluminum [11]. Due to the hardness difference between White Layers and bulk material, Umbrello et al. introduced a hardness-based yield potential for the prediction of the thickness of different layers when hard turning AISI 52100 [12], which can be also coupled with the Zener-Hollomon parameter to calculate the grain size [13]. Recently, Buchkremer and Klocke developed a thermodynamics-based model to simulate the dynamic recrystallization process during orthogonal cutting of AISI 4140 in the quenched and tempered state [14].

All these introduced models are able to predict grain size refinement by dynamic recrystallization. However, depending on the model, many material parameters have to be calibrated in a time-consuming sensitivity analysis and/or even iteratively. Besides, the calculation time of finite element (FE) simulations must be taken into account. At last, numerical calculation are invariable with regard to their preset boundary conditions such as predefined workpiece material parameters or tool micro geometry. In contrast, in the real cutting process, even small locally inhomogeneous material properties or, for example, progressive tool wear have an effect on the spatially resolved process state variables and thus on the workpiece material modifications in the rim zone. While the measurement of these process state variables is impossible in most machining processes, the measurement of the integral process forces is part of the current standard in machining industry. Dynamometers, strain gauge based systems or the calculation of the cutting force from the power of the machine drives are usually used for this purpose [15]. Therefore, an analytical and fast computing approach based on the cutting force could be beneficial in order to estimate locally resolved process state variables and thus enable an in-process estimation of the current Surface Integrity state.

\section{Cutting force based soft-sensor development}

The aim of this study was to develop and validate a cutting force based Soft-Sensor for the estimation of the maximum White Layer thickness $d_{\mathrm{WL} \text {,max }}$ when hard cutting AISI 4140. As previously described, numerical finite element modelling can be a powerful tool in predicting changes in grain size. Nevertheless, from a practical point of view, the in-process knowledge of current maximum White Layer thickness using fast computing models is of greater significance than the determination of exact grain sizes. Since a direct and non-destructive in-process measurement of the White Layer is yet not possible, a Soft-Sensor was developed in order to estimate the White Layer thickness.

The design of the developed Soft-Sensor is illustrated in Figure 1. Machine available process parameters such as cutting speed $v_{c}$, undeformed chip thickness $h$ and width of cut $b$ are used as a first input. In-Process measured cutting forces are then utilized in order to analytically compute the heat partition into the workpiece and the steady state temperature fields for the given specific cutting conditions using the Jaeger solution [16]. With the computed temperature field, the maximum depth of White Layer is predicted by adopting the critical initiation temperature $T_{\text {crit }}=0.4 \cdot T_{\text {melt }}=614.14^{\circ} \mathrm{C}$, from Meyers et al., above which dynamic recrystallization and thus White Layer formation may occur [17]. To validate both stationary temperature fields and max. White Layer thickness, numerical cutting simulations were conducted and the actual thickness of White Layer was examined via light microscopy from real specimen.

\section{Experimental setup}

All orthogonal cutting experiments were performed on a vertical external broaching machine tool of type FORST RASX $8 \times 2200 \times 600 \mathrm{M} / \mathrm{CNC}$, see Figure 2 . The grooving insert tool was clamped onto a Kistler Z21289 piezoelectric dynamometer with a measurement range from -80 to $80 \mathrm{kN}$ in cutting force direction. The workpieces of size $80 \mathrm{~mm} \times 40 \mathrm{~mm} \times 3.3 \mathrm{~mm}$ were fixed in the machine slide and performed the main cutting movement against the 


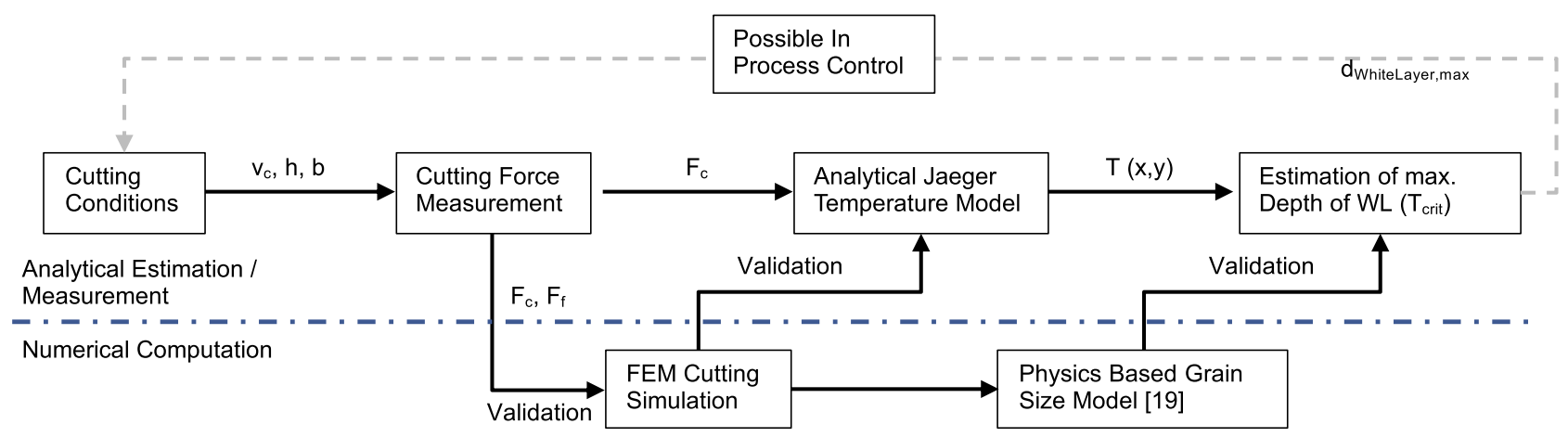

Figure 1: Flow chart of the Soft-Sensor.
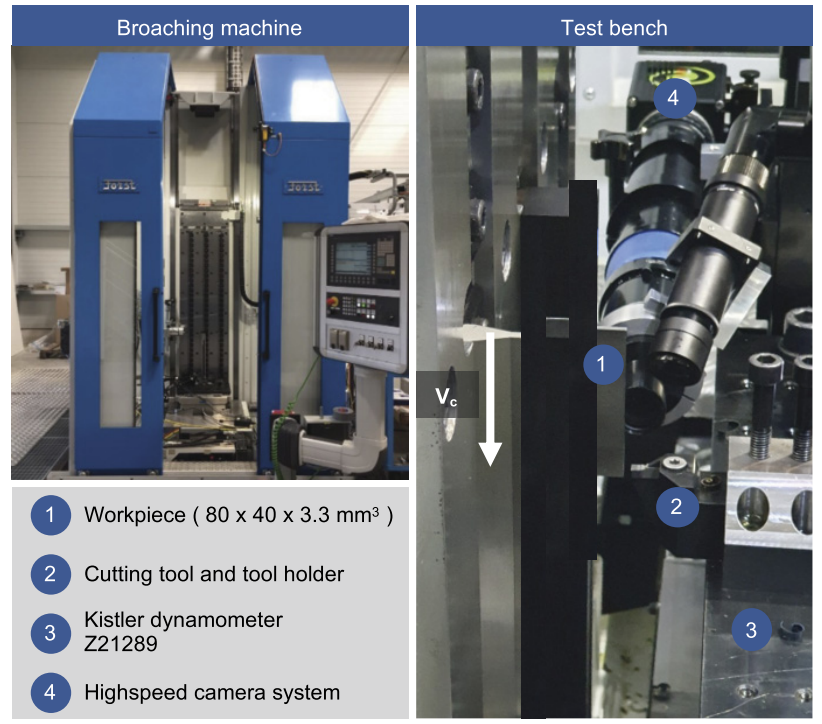

Figure 2: Experimental setup for orthogonal cutting experiments [20].

motionless tool. Besides the force measurement, the experimental setup offers the possibility to capture the cutting process using ultra-high-speed camera techniques. The specimens were each individually quenched and tempered to a mean hardness of $\delta=48 \mathrm{HRC}$ according to $[18,19]$.

A full-factorial variation of cutting speed $v_{c}$ and the undeformed chip thickness $h$ was applied in this study. The used cutting parameters were $v_{c}=50,100$, and $150 \mathrm{~m} / \mathrm{min}$ for the cutting speed and $h=0.05,0.10,0.15$, and $0.20 \mathrm{~mm}$ for the undeformed chip thickness. All experiments were repeated twice. In-between individual cuts, tool wear was examined and measured optically in order to ensure an undamaged cutting edge with a maximum width of flank wear $V B_{\max }=20 \mu \mathrm{m}$. As cutting tools, coated cemented carbide (Sandvik H13A) grooving inserts with a rake angle $y=6^{\circ}$ and a flank angle of $\alpha=3^{\circ}$ have been utilized. The mean cutting edge radius was determined to be $r_{\beta}=66 \mu \mathrm{m}$ with a standard deviation of $2.7 \mu \mathrm{m}$ for all cutting tools.

\section{Finite element modelling of hard cutting}

In the following section, the finite element model in Abaqus/Explicit for the simulation of orthogonal cutting based on the Coupled-Eulerian-Lagrangian (CEL) method is presented. Then, a suitable material model for a visco-plastic material behavior is given. Finally, a thermodynamics-based grain refinement model is shown for the modelling of workpiece surface modifications.

\subsection{Finite element model}

During the machining processes, high strains and strain rates occur, which aggravates modelling due to extreme mesh distortion. For that reason, the mesh insensitive Coupled-Eulerian-Lagrangian approach was chosen, where the chip formation was realized without any re-meshing, element deletion or damage criteria. The 3D model was built up with the commercial FE software Abaqus/Explicit 2018. Due to the combined thermomechanical loads in cutting, a coupled temperaturedisplacement analysis step was used. The friction was considered by Coulomb's law. In this work, the friction coefficient $\mu$ was implemented as a function of the cutting velocity $\mu\left(v_{c}\right)$ based on the approach in [18]. The model design is depicted together with some of the boundary conditions and material flow directions in Figure 3.

In the CEL method, a so-called Euler-environment can be defined as a mixture of 'material' and 'void'. The mate- 


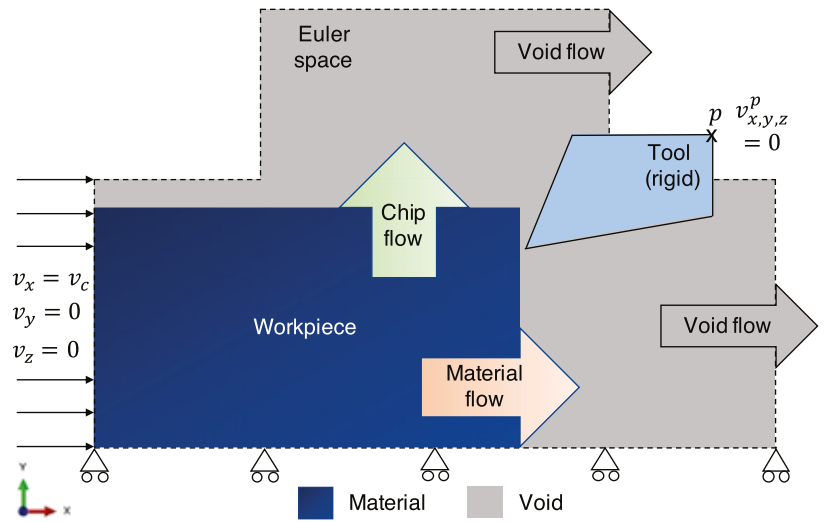

Figure 3: Schematic representation of the finite element model of orthogonal cutting using CEL method.

rial part can be interpreted as workpiece. Since the Eulerenvironment is fixed in space, the workpiece material can flow through it with a prescribed cutting velocity $v_{c}$. In addition to the material part, the cutting velocity was also applied to the voids as a boundary condition. Due to the fact that the CEL method was only available in 3D, the material flow in $z$-direction was blocked. The cutting tool was modelled using the Lagrange approach as a rigid body with $v_{x, y, z}^{p}=0$ at the reference point $p$. The geometry of the cutting tool was chosen analogous to the cutting experiments.

Both workpiece and void were meshed with eightnode thermally coupled linear brick elements with reduced integration point (EC3D8RT), while the tool was meshed with eight-node trilinear displacement and temperature elements with eight integration points (C3D8T).

The mesh size was set to $0.9 \mu \mathrm{m}$ where the workpiece rim zone modification is of interest, while the coarsest mesh size was determined to be around $3 \mu \mathrm{m}$. The thickness of the model in $z$-direction was $2 \mu \mathrm{m}$, which is equal to thickness of an element. In order to reduce the computational cost a mass scaling technique was employed.

The physical material parameters of cutting material (tool) and workpiece are given in the Table 1.

This FEM model was validated based on the previously obtained process forces. Figure 4 exemplarily shows the comparison between simulated and measured normalized cutting $F_{c}$ and feed $F_{f}$ forces at different cutting speeds $v_{c}=50,100$, and $150 \mathrm{~m} / \mathrm{min}$ and cutting depths $h=0.05$ and $0.1 \mathrm{~mm}$. It can be deduced that the (normalized) cutting forces were generally slightly overestimated in the simulations, whereas the (normalized) feed forces were underestimated. The max. deviations regarding the normalized cutting and feed forces were 35 and $86 \mathrm{~N} / \mathrm{mm}$, respectively, which can be considered a good agreement.
Table 1: Cutting material (Sandvik H13A) and workpiece (AISI 4140 QT) material properties [14].

\begin{tabular}{lrrr}
\hline Properties & \multicolumn{1}{c}{$\begin{array}{l}\text { Cutting } \\
\text { material }\end{array}$} & Workpiece & Unit \\
\hline Young's modulus & $6 \cdot 10^{5}$ & 204223 & $\mathrm{MPa}$ \\
Poisson ratio & 0.2 & 0.3 & - \\
Density & $1.5 \cdot 10^{-6}$ & $7.612 \cdot 10^{-6 \star}$ & $\mathrm{kg} / \mathrm{mm}^{3}$ \\
Heat conductivity & 66.3 & 42.6 & $\mathrm{~W} / \mathrm{mK}$ \\
Specific heat & 250 & $2 \cdot 10^{-4} \cdot T^{2}+477.04$ & $\mathrm{~J} / \mathrm{kgK}$ \\
& & $-0.0654 \cdot T$ & \\
Initial grain size & - & 680 & $\mathrm{~nm}$ \\
\hline * at $0.4 \cdot T_{\text {met. }}$ & & &
\end{tabular}

* at $0.4 \cdot T_{\text {melt }}$.
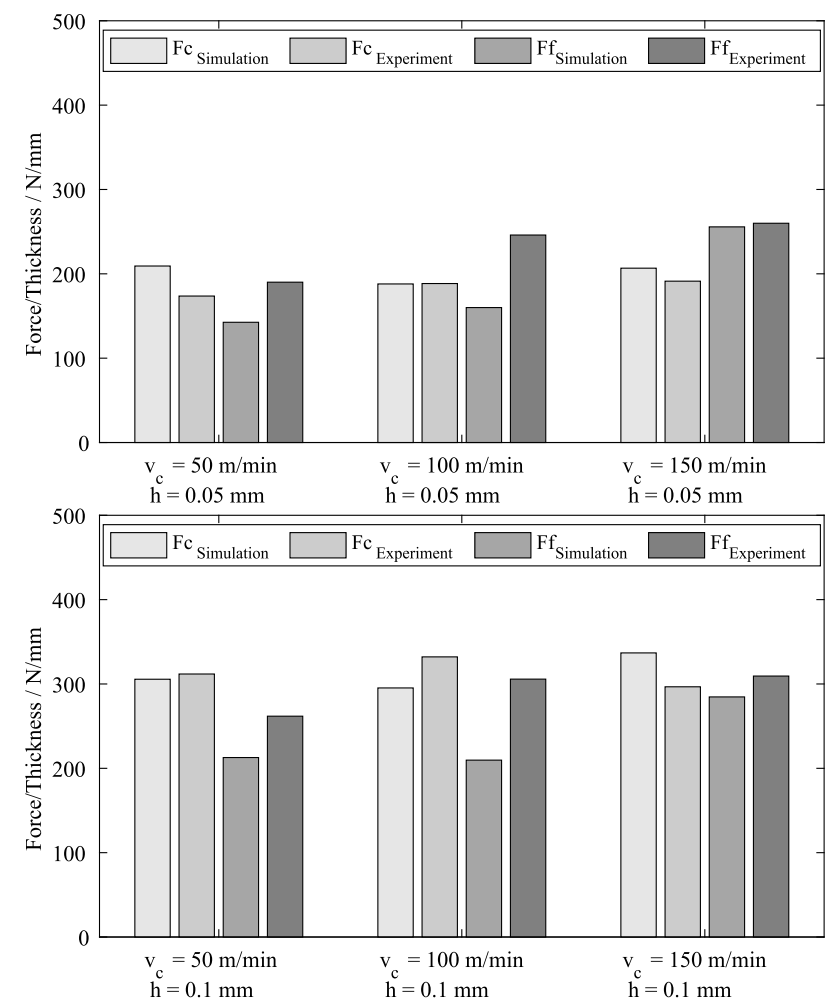

Figure 4: Comparison of the predicted and experimentally measured normalized cutting and feed forces at cutting speeds $v_{c}=50,100$, and $150 \mathrm{~m} / \mathrm{min}$ and cutting depths $h=0.05$ and $0.1 \mathrm{~mm}$.

A reason for the general poor prediction of $F_{f}$ in CEL simulations initial wear can be mentioned [21], while the prediction of cutting forces depends on the material model.

\subsection{Material model}

For the modelling of the visco-plastic material behavior during the cutting process, the empirical JohnsonCook model was used, which considers the influence of 
strain, strain rate and temperature on the yield stress [22]. This material model was programmed in FORTRAN as a VUHARD user subroutine in Abaqus/Explicit. The definition of the yield function $\sigma_{y}^{J C}$ is given in Equation (1).

$$
\begin{aligned}
& \sigma_{y}^{J C}\left(\overline{\bar{\varepsilon}}^{p l}, \dot{\bar{\varepsilon}}^{p l}, T\right)=\left[A+B \cdot\left(\overline{\bar{\varepsilon}}^{p l}\right)^{n}\right] . \\
& {\left[1+C \cdot \ln \left(\frac{\dot{\bar{\varepsilon}}^{p l}}{\dot{\bar{\varepsilon}}_{0}^{p l}}\right)\right] \cdot\left[1-\left(\frac{T-T_{0}}{T_{\text {melt }}-T_{0}}\right)^{m}\right]}
\end{aligned}
$$

Here, $A$ equates for the yield stress at reference temperature $T_{0}$ and strain rate $\dot{\bar{\varepsilon}}_{0}^{p l} . B$ is the strain hardening coefficient, $n$ is the exponent of strain hardening, $C$ and $m$ are the material parameters that represent the coefficient of strain rate hardening and the thermal softening exponent, respectively. While $T_{\text {melt }}$ refers to the melting temperature, $T$ represents the current temperature. The material constants of quenched and tempered steel AISI 4140 are summarized in Table 2.

Table 2: Jonson-Cook model parameters of AISI 4140 [14].

\begin{tabular}{rrrrrr}
\hline$A / \mathrm{MPa}$ & $B / \mathrm{MPa}$ & $n$ & $\mathrm{C}$ & $\mathrm{m}$ & $\dot{\bar{\varepsilon}}_{0}^{p l} / \mathrm{s}^{-1}$ \\
\hline 1450 & 910 & 0.45 & 0.034 & 0.328 & 0.001 \\
\hline$T_{0} /{ }^{\circ} \mathrm{C}$ & $T_{\text {melt }} /{ }^{\circ} \mathrm{C}$ & & & & \\
\hline 20 & 1536 & & & & \\
\hline
\end{tabular}

\subsection{Modelling of white layer formation based on DRX}

In the current work, a thermodynamically motivated DRX framework, which was developed by Buchkremer and Klocke, was implemented to predict the thickness of the White Layer in the workpiece rim zone [14]. In the following, the model is briefly introduced.

The grain size evolution is formulated based on the variation of free Helmholtz energy $\mathrm{d} \psi$, which is given in Equation (2).

$$
\mathrm{d} \psi=\underbrace{\left(\mathrm{d} e_{m e}+\mathrm{d} e_{t h}+\mathrm{d} e_{a}\right)}_{\mathrm{d} u}-(s \cdot \mathrm{d} T+T \cdot \mathrm{d} s),
$$

where $s$ represents the entropy, $\mathrm{d} u, \mathrm{~d} e_{m e}, \mathrm{~d} e_{t h}, \mathrm{~d} e_{a}, \mathrm{~d} s$ and $\mathrm{d} T$ stand for the change in internal energy, mechanical energy, thermal energy, interface energy, entropy and temperature, respectively.

The sign of the variation of free Helmholtz energy has a physical significance. In this model $\mathrm{d} \psi<0$ indicates that dynamic recrystallization occurs spontaneously, which makes this condition one of the criterion that must be fulfilled for DRX to take place. In addition to that, a critical temperature $T_{\text {crit }}=0.4 \cdot T_{\text {melt }}$ and a critical amount of stored specific mechanical energy $e_{\text {crit }}=580 \mathrm{MPa}$ have to be exceeded as well.

If all three critical conditions are satisfied, the recrystallized grain size $d_{t}$ in mm can be calculated as follows,

$$
d_{t}=\frac{3 \cdot \gamma_{g b}(T)}{\frac{3 \cdot \gamma_{g b}(T)}{d_{t-1}}+\Omega(T) \cdot 10 \% \cdot \mathrm{d} e_{m e}}
$$

with $d_{t-1}$ as the grain size from previous time step, $\gamma_{g b}$ in $\mathrm{mJ} / \mathrm{mm}^{2}$ as the grain boundary energy and $\Omega$ as the fraction of dislocation energy which is transformed to the interface energy $\mathrm{d} e_{a}$ in MPa. The corresponding definitions are given in Equations (4-6) [14].

$$
\begin{gathered}
\gamma_{g b}(T)=-4.90 \cdot 10^{-7} \cdot T+4.606 \cdot 10^{-3} \\
\Omega(T)=1.667 \cdot \frac{T}{T_{\text {melt }}}-0.667 \\
d e_{a}=\Omega(T) \cdot 10 \% \cdot \mathrm{d} e_{m e}
\end{gathered}
$$

This DRX model was programmed in FORTRAN as a VUHARD user subroutine and integrated into Abaqus/Explicit. The flow chart of the implementation is shown in Figure 5.

\section{Analytical in-process temperature field calculation}

As previously shown by the authors, the Jaeger solution [16] can be utilized to compute accurate temperature fields for various cutting processes [23, 24]. The stationary temperature field induced by a moving band heat source in the two-dimensional space of a semi-infinite solid without heat loss at the surface is given by the Equation (7).

$$
\begin{aligned}
& T(x, y)=\frac{\dot{q}^{\prime \prime}}{\pi \cdot \lambda} \int_{0}^{h} \exp \left[\frac{v \cdot(x-\bar{x})}{2 a}\right] \cdot K_{0} . \\
& {\left[\frac{v}{2 a} \cdot \sqrt{(x-\bar{x})^{2}+y^{2}}\right] \mathrm{d} \bar{x}}
\end{aligned}
$$

Now, assuming that all process heat which is induced into the workpiece surface can be summarized as this specific moving band heat source $\dot{q}^{\prime \prime}$, the steady state temperature at a certain position $(x, y)$ of the workpiece can be calculated (Figure 6).

While $x$ and $y$ are the coordinates parallel and vertical to the workpiece surface, $K_{0}$ corresponds to the Bessel 


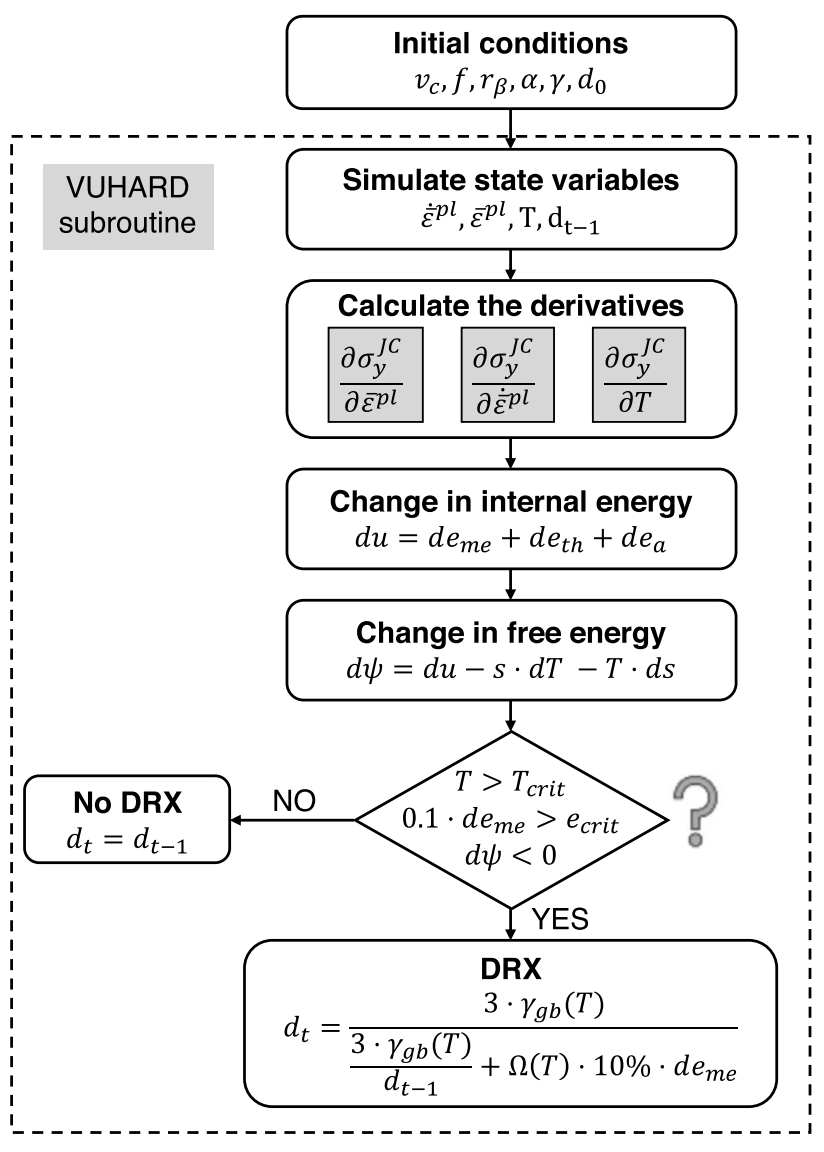

Figure 5: Flow chart of the implemented free Helmholtz energy DRX model with Johnson-Cook material model in Abaqus/Explicit.

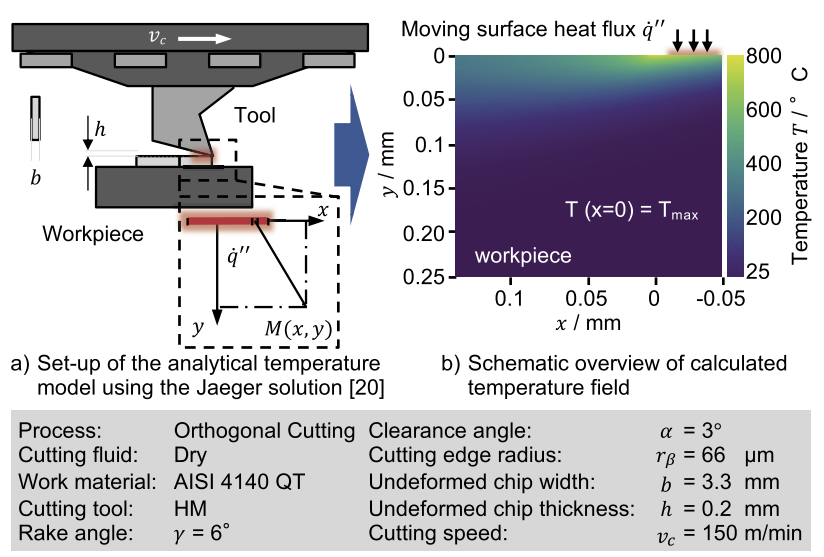

Figure 6: Analytical temperature modelling using the Jaeger solution when hard cutting AISI 4140.

function of second order or zero. The temperature diffusivity $a$ and heat conductivity of the workpiece material were set to $a=10.87 \mathrm{~mm}^{2} / \mathrm{s}$ and $\lambda=42 \mathrm{~W} / \mathrm{mK}$ [14]. The velocity of the moving heat source $v$ was implemented according to the individual cutting speed $v_{c}$. The amount of the result- ing heat source $\dot{q}^{\prime \prime}$ was calculated according to:

$$
\dot{q}^{\prime \prime}=\frac{\dot{Q}_{\mathrm{WP}}}{b \cdot h}
$$

using the undeformed chip thickness $h$ and the width of cut $b$ which was defined by the width of the specimen to $b=3.3 \mathrm{~mm}$. The total heat flow into the workpiece $\dot{Q}_{\mathrm{WP}}$ was derived from the total cutting power and the individual heat partition $B_{W P}$ into the workpiece:

$$
\dot{Q}_{\mathrm{WP}}=F_{c} \cdot v_{c} \cdot B_{\mathrm{WP}}
$$

It was previously shown that the heat partition into the workpiece can be estimated according to a Péclet-number based power function [25]:

$$
B_{\mathrm{WP}}=0.4815 \cdot N_{\mathrm{Pe}}^{-0.302}
$$

using:

$$
N_{\mathrm{Pe}}=v_{c} \cdot \frac{h}{a}
$$

Besides the workpiece material physical constants such as the heat conductivity, both, the cutting parameters and the cutting force $F_{c}$ are the only input parameters of the heuristic, that is why a fast in-process computation of the temperature fields became possible.

\section{Result and discussion}

Using the Jaeger solution as described, the need for a validation of the calculated temperature fields emerges. Since the measurement of the whole temperature field in particular in the shear zone and around the tool tip is challenging in the cutting process [26], the aforementioned FEM model has been used as the primary source of validation. As the exact position of the moving band heat source in $x$-direction relative to the cutting tool is of no importance in the assumed steady state and to ensure comparability between FE simulation and analytical Jaeger solution, the zero point $x=0$ of both temperature fields was shifted to the $x$-position of the highest temperature below the workpiece surface $\left(T_{\max }=T(x=0)\right)$.

A comparison of the qualitative trends was conducted using two different levels of observation. First, Figure 7a shows a comparison of the temperature profile in $y$-direction starting at the maximum temperature $T_{\max }(x=0, y)$ beneath the machined workpiece surface. Second, Figure $7 \mathrm{~b}$ gives an overview of the temperature profile over the machine surface $T(x, y=0)$ behind the 

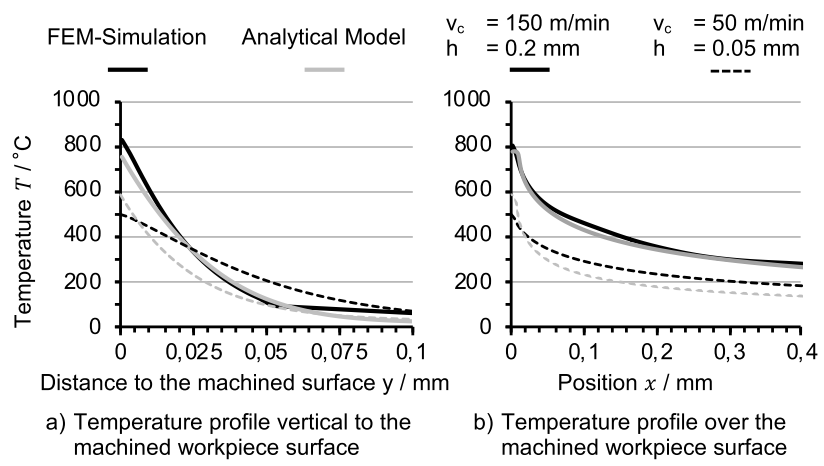

b) Temperature profile over the machined workpiece surface

Figure 7: Comparison of analytical and FEM-based calculation of temperature profiles.

cutting edge. Two examples of this study are presented here. Besides a cutting condition with a high cutting speed $v_{c}=150 \mathrm{~m} / \mathrm{min}$ and a high undeformed chip thickness $h=0.2 \mathrm{~mm}$, the temperature profiles of the low cutting speed $v_{c}=50 \mathrm{~m} / \mathrm{min}$ and a low undeformed chip thickness $h=0.05 \mathrm{~mm}$ are shown.

In case of the first cutting condition, the qualitative overlap of the calculated temperature profiles between numerical solution and analytical approach appears to be accurate both for the profile vertical and alongside the machined workpiece surface (Figure 7, solid lines). In contrast, for the low cutting speed and lower undeformed chip thickness, the simulated profiles differ, especially vertical to the machined workpiece surface.

In addition to the qualitative comparison, the discrete deviation between both models has been calculated. As White Layer formation is known to appear only in the direct vicinity of the machined workpiece surface, the accuracy of the Soft-Sensor is assessed by its validity in this same region. Therefore, the percentage deviation between the calculated temperature profiles in dependence on the distance to the machined surface is given in Figure 8.

First, summarizing all cutting conditions, a mean deviation of about $10 \%$ was reached in a distance to the machined surface lower than $y_{\max }=20 \mu \mathrm{m}$. The lowest deviations could be achieved for cutting speeds higher than $v_{c}=50 \mathrm{~m} / \mathrm{min}$ and undeformed chip thicknesses higher than $h=0.05 \mathrm{~mm}$, where deviations drop down to about $1 \%$ of the via FEM simulated temperature values. On the contrary, especially for the low undeformed chip thickness of $h=0.05 \mathrm{~mm}$, deviations can rise up to about $35 \%$ of the target value.

To further demonstrate this effect, Figure $8 \mathrm{~b}$ shows the percentage deviation for all cutting conditions with a cutting speed $v_{c}>50 \mathrm{~m} / \mathrm{min}$ and an undeformed chip thickness of $h>0.05 \mathrm{~mm}$. Here, a mean deviation of $5 \%$ to $8 \%$ could be reached in the direct vicinity of the machined

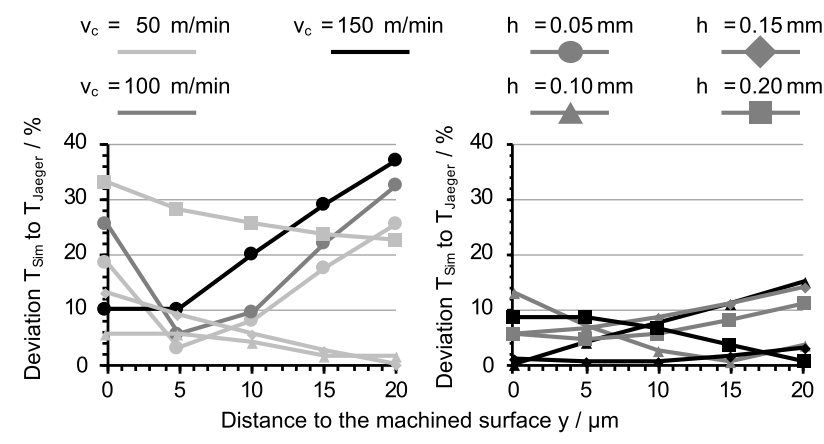

a) Deviations for cutting conditions

b) Deviations for cutting conditions with with $\mathrm{v}_{\mathrm{c}}=50 \mathrm{~m} / \mathrm{min}$ or $\mathrm{h}=0.05 \mathrm{~mm}$

Figure 8: Quantitate evaluation of deviation between analytical and FEM-based temperature modelling.

workpiece surface. Furthermore, a maximum deviation of about $15 \%$ of the target value was observed in a depth of $y=20 \mu \mathrm{m}$.

Even though the percentage deviation of analytical and numerical temperature prediction in the direct surface vicinity reduces to lower than $10 \%$ for higher undeformed chip thicknesses and higher cutting speeds, a considerable error remains. This error can be attributed to several simplifications in the given modelling approach. First, the Jaeger model assumes a moving heat band source on the surface without heat generation of the rigid body whereas in the cutting process, heat generation due to plastic deformation even may occur on the machined surface level near the tool tip. Second, especially the calculation of the heat partition into the workpiece was simplified using an Péclet-number based power function. Furthermore, the length of the moving band heat source was set to be the undeformed chip thickness which does not need to be a physically correct assumption. These challenges will have to be addressed in a future work especially for lower undeformed chip thicknesses and cutting speeds.

At last, the calculated maximum depth of White Layer $d_{\mathrm{WL}}$ depending on the cutting conditions was investigated. For the DRX-FEM-model, White Layer thickness ranged from about $d_{\mathrm{WL}}=3 \mu \mathrm{m}$ to $d_{\mathrm{WL}}=7 \mu \mathrm{m}$. As expected, the obtained values increased for higher cutting speeds which can be related to the higher thermal load induced by the cutting process. In detail, maximum calculated temperatures for a cutting speed of $v_{c}=150 \mathrm{~m} / \mathrm{min}$ were about $150^{\circ} \mathrm{C}$ higher on the surface than those for the lower cutting speed of $v_{c}=50 \mathrm{~m} / \mathrm{min}$. Subsequently, the critical initiation temperature $T_{\text {crit }}$ was exceeded in a greater depth for the higher cutting speeds. Figure 9a offers a comparison between the numerical and analytical calculated thickness of White Layer and the measured value for an 


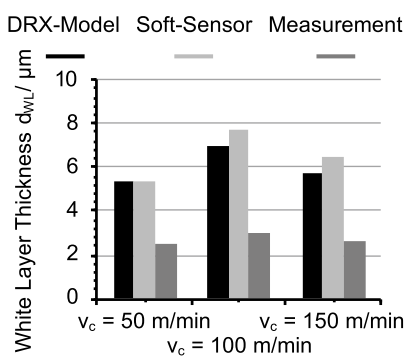

a) Comparison between calculated and measured White Layer thickness

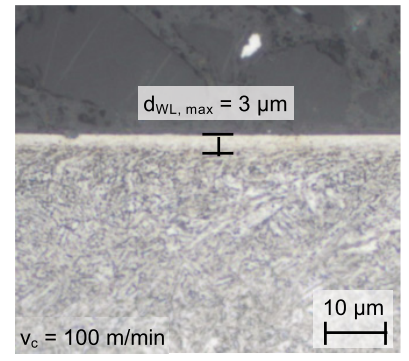

b) Etched surface rim zone of specimen

Figure 9: White Layer thickness when cutting AISI 4140 with an undeformed chip thickness of $h=0.2 \mathrm{~mm}$.

undeformed chip thickness of $h=0.2 \mathrm{~mm}$. As temperature fields tend to become inaccurate for cutting conditions with $N_{\mathrm{Pe}}<15$, deviations logically rise for those cutting conditions.

In order to determine the experimentally induced White Layer thickness, specimen which where cut with an undeformed chip thickness of $h=0.2 \mathrm{~mm}$ were dissected in longitudinal and transversal direction, etched and then examined under light microscopy (Figure 9b). Afterwards, $d_{\mathrm{WL}, \max }$ was measured manually. For all investigated specimen, the measured value White Layer thickness ranged between $d_{\mathrm{WL}}=2.5$ and $3.5 \mu \mathrm{m}$ which is in the same order of magnitude as the previously estimated maximum White Layer thickness. Nevertheless, all measured values were below those predicted by the analytical or numerical model. This deviation may both be explained by model inaccuracies due to its simplification or insufficient detail resolution as well as by the imprecise optical measurement method.

\section{Conclusion and outlook}

In this study, a cutting force based Surface Integrity SoftSensor was developed using an analytical approach based on the Jaeger moving band heat source solution and validated via an FEM model with an implemented DRX framework for the prediction of White Layer thickness when hard machining AISI 4140. The developed concept of a the Soft-Sensor and its analytical model was able to predict the temperature profiles more accurately at higher cutting speeds and higher undeformed chip thicknesses than for lower cutting conditions. As the model only uses physical material data such as the thermal diffusivity, the given cutting parameters $v_{c}, h, b$ and lastly the cutting force $F_{c}$ as an input, no calibration procedure was needed. The remain- ing model inaccuracies regarding the calculated temperature fields can mainly be attributed to the necessary model simplifications enabling a fast computation.

On basis of the calculated temperature fields, the maximum White Layer thickness was estimated using a critical initiation temperature for White Layer formation of $T_{\text {crit }}=0.4 \cdot T_{\text {melt }}$. In comparison with the validated FEMDRX model, a good agreement of the maximum depth of White Layer was achieved. Nevertheless, the estimated values differed from those obtained via optical measurement by about the factor of 2 which has to be addressed in the future.

Due to its analytical and fast computing nature, the presented Soft-Sensor concept can be implemented in a Surface-Integrity focused process monitoring and control in the future. For this purpose, several further investigations have to be conducted. In terms of the analytical and numerical models, the influence of different workpiece heat treatments and tool geometries has to be investigated as well as its transfer to other workpiece materials. The accuracy of the used analytical temperature model has to be enhanced by individually adjusting the heat partition into the workpiece and the width of the moving heat source for individual cutting conditions. The demonstrated FEM models have to be further improved and validated using non integral validation parameters such as strain and strain rate fields [20]. In addition, the impact of the mechanical workpiece loading has to be examined and added to the White Layer prediction model.

Lastly, the presented approach has to be transferred and connected to the machine tool in order to in-process calculate the temperature fields from measured cutting forces. Later on, the Soft-Sensor can be extended from orthogonal cutting to industry relevant processes such as turning. Therefore, it is indispensable to implement a tool and workpiece geometry as well as process parameter depended engagement simulation of the cutting microgeometry. With the knowledge of the given engagement conditions, the two-dimensional Jaeger solution has to be transferred to the three-dimensional case, too.

Funding: The scientific work has been supported by the German Research Foundation (DFG) within the research priority programs SPP 2086 and SPP 2183.

\section{References}

1. I. S. Jawahir, E. Brinksmeier, R. M’Saoubi, D. K. Aspinwall, J. C. Outeiro, D. Meyer, D. Umbrello, and A. D. Jayal. Surface integrity 
in material removal processes: Recent advances. CIRP Annals, 60(2):603-626, 2011.

2. F. Borchers, B. Clausen, S. Eckert, L. Ehle, J. Epp, S. Harst, M. Hettig, A. Klink, E. Kohls, H. Meyer, M. Meurer, B. Rommes, S. Schneider, and R. Strunk. Comparison of Different Manufacturing Processes of AISI 4140 Steel with Regard to Surface Modification and Its Influencing Depth. Metals, 10:895, 2020.

3. Wim H. Sillekens, Sean R. Agnew, Neale R. Neelameggham, and Suveen N. Mathaudhu, editors. Magnesium Technology 2011. John Wiley \& Sons, Inc., Hoboken, NJ, USA, 2011.

4. B. J. Griffiths. White Layer Formations at Machined Surfaces and Their Relationship to White Layer Formations at Worn Surfaces. Journal of Tribology, 107(2):165-171, 041985.

5. Baofa Zhang, Wanci Shen, Yingjie Liu, Xiangyun Tang, and Yuanfei Wang. Microstructures of surface white layer and internal white adiabatic shear band. Wear, 211(2):164-168, 1997.

6. J. Yanagimoto, K. Karhausen, A. J. Brand, and R. Kopp. Incremental formulation for the prediction of flow stress and microstructural change in hot forming. Journal of Manufacturing Science and Engineering, 120(2):316, 1998.

7. Florian Ambrosy, Frederik Zanger, and Volker Schulze. FEM-simulation of machining induced nanocrystalline surface layers in steel surfaces prepared for tribological applications. CIRP Annals, 64(1):69-72, 2015.

8. Y. Estrin, L. S. Tóth, A. Molinari, and Y. Bréchet. A dislocation-based model for all hardening stages in large strain deformation. Acta Materialia, 46(15):5509-5522, 1998.

9. Hongtao Ding and Yung C. Shin. Multi-physics modeling and simulations of surface microstructure alteration in hard turning. Journal of Materials Processing Technology, 213(6):877-886, 2013.

10. Binxun Li, Song Zhang, Ruize Hu, and Xinzhi Zhang. Dislocation density and grain size evolution in hard machining of h13 steel: numerical and experimental investigation. Journal of Materials Research and Technology, 2020.

11. Hongtao Ding and Yung Shin. Dislocation density-based grain refinement modeling of orthogonal cutting of titanium. Journal of Manufacturing Science and Engineering, 136, 2014.

12. Domenico Umbrello, Jiang Hua, and Rajiv Shivpuri. Hardness-based flow stress and fracture models for numerical simulation of hard machining aisi 52100 bearing steel. Materials Science and Engineering: A, 374(1):90-100, 2004.

13. S. Caruso, Serena Renzo, Domenico Umbrello, Anshu Jayal, 0 . W. Dillon, and I. s. Jawahir. Finite element modeling of microstructural changes in hard turning. Advanced Materials Research, 223:960-968, 042011.

14. S. Buchkremer and F. Klocke. Modeling nanostructural surface modifications in metal cutting by an approach of thermodynamic irreversibility: Derivation and experimental validation. Continuum Mechanics and Thermodynamics, 29(1):271-289, 2017.

15. R. Teti, Krzysztof Jemielniak, G. E. O’Donnell, and David Dornfeld. Advanced monitoring of machining operations. CIRP Annals - Manufacturing Technology, 59:717-739, 122010.

16. J. C. Jaeger. Moving sources of heat and the temperature of sliding contacts. Proceedings of the Royal Society of New South Wales, 76:203-224, 1942.
17. Yongbo Xu, Jinghua Zhang, Yilong Bai, and Marc André Meyers. Shear localization in dynamic deformation: Microstructural evolution. Metallurgical and Materials Transactions $A$, 39(4):811, 2008.

18. Stefan Buchkremer, Fritz Klocke, and Benjamin Döbbeler. Impact of the heat treatment condition of steel AISI 4140 on its frictional contact behavior in dry metal cutting. Journal of Manufacturing Science and Engineering, 138, 2016.

19. S. Buchkremer. Irreversible thermodynamics of nano-structural surface modifications in metal cutting. Dissertation, 2017. RWTH Aachen; IIF-Institut für Industriekommunikation und Fachmedien $\mathrm{GmbH}$.

20. Markus Meurer, Thorsten Augspurger, Berk Tekkaya, Daniel Schraknepper, André Pontes Lima, and Thomas Bergs. Development of a methodology for strain field analysis during orthogonal cutting. Procedia CIRP, 87:444-449, 2020.

21. Anders Nordgren, Baktash Zargari Samani, and Rachid M. Saoubi. Experimental study and modelling of plastic deformation of cemented carbide tools in turning. Procedia CIRP, 14:599-604, 2014.

22. Gordon R. A Constitutive model and data for materials subjected to large strains, high strain rates, and high temperatures, pages 541-547, 1983.

23. Thomas Bergs, Bingxiao Peng, Daniel Schraknepper, and Thorsten Augspurger. A novel approach to determine the cutting temperature under consideration of the tool wear. ASME 2020 15th International Manufacturing Science and Engineering Conference, 2020.

24. Thorsten Augspurger, Markus Meurer, Hui Liu, Patrick Mattfeld, and Thomas Bergs. Experimental study of the connection between process parameters, thermo-mechanical loads and surface integrity in machining inconel 718. Procedia CIRP, 87:59-64, 2020. 5th CIRP Conference on Surface Integrity (CSI 2020).

25. Thorsten Augspurger, Thomas Bergs, and Benjamin Döbbeler. Measurement and Modeling of Heat Partitions and Temperature Fields in the Workpiece for Cutting Inconel 718, AISI 1045, Ti6Al4V, and AlMgSi0.5. Journal of Manufacturing Science and Engineering, 141(6):061007, 042019.

26. T. Augspurger, T. Bergs, B. Döbbeler, and A. Lima. Methodology for the Measurement of the Heat Partitioning by Thermal Imaging in the Orthogonal Cutting Process. Journal of Heat Transfer, 141(7):072101, 052019.

\section{Bionotes}

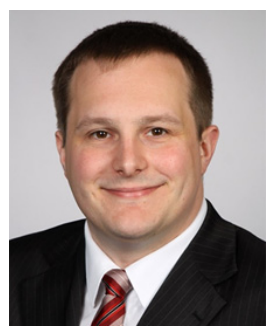

Markus Meurer

RWTH Aachen University, Laboratory for Machine Tools and Production Engineering (WZL), Aachen, Germany m.meurer@wzl.rwth-aachen.de

(11/2017-now) Laboratory for Machine Tools and Production Engineering (WZL), RWTH Aachen University: Group Leader - Modelling 
and Evaluation of Cutting Processes, Cutting Technology Department; (12/2016-now) Laboratory for Machine Tools and Production Engineering (WZL), RWTH Aachen University: Research Engineer, Cutting Technology Department; (04/2014-11/2016) RWTH Aachen University, Aachen: Production Technology, Master of Science. Thesis Topic: Design and construction of a measuring method for determining process-specific parameters in cooling lubricants as a basis for online process monitoring; (08/2014-12/2014) Korea University, Seoul, South Korea - Graduate School for Mechanical Engineering: Student Exchange with focus on process modelling and robot control; (10/2008-04/2014) RWTH Aachen University, Aachen: Mechanical Engineering, Bachelor of Science. Field of specialisation: Design and Construction.

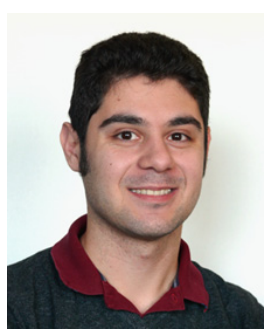

\section{Berk Tekkaya}

RWTH Aachen University, Integrity of Materials and Structures, Steel Institute (IEHK), Aachen, Germany berk.tekkaya@iehk.rwth-aachen.de

(10/2018-now) Steel Institute (IEHK), RWTH Aachen University: Research Assistant, Damage Tolerance; (/2016-10/2018) TU-Dortmund University, Dortmund: Mechanical Engineering, Master of Science. Field of specialisation: Modelling and Simulation in Mechanics. Thesis Topic: Extension of a Material Model for the Simulation of Coupled Hydrogen Diffusion to Include Damage Initiation; (10/201103/2017) TU-Dortmund University, Dortmund: Mechanical Engineering, Bachelor of Science. Field of specialisation: Modelling and Simulation in Mechanics.

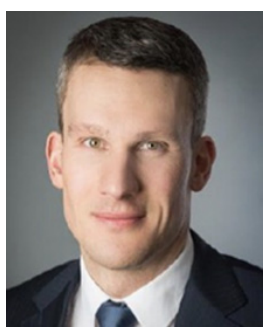

\section{Dr. Thorsten Augspurger}

RWTH Aachen University, Laboratory for Machine Tools and Production Engineering (WZL), Aachen, Germany t.augspurger@wzl.rwth-aachen.de

(03/2016-now) Laboratory for Machine Tools and Production Engineering (WZL), RWTH Aachen University: Group Leader - Productand Process Monitoring, Cutting Technology Department; (09/2015now) Laboratory for Machine Tools and Production Engineering (WZL), RWTH Aachen University: Research Engineer, Cutting Technology Department; (10/2018) Doktoringenieur (Dr.-lng.) with honours (summa cum laude): Title: "Thermal analysis of the milling process"; (01/2014-08/2015) Fraunhofer Institute for Production Technology (IPT), RWTH Aachen University: Research Engineer, Cutting Technology Department; (10/2012-12/2013) Bilfinger Power Systems GmbH: Quality engineer; (10/2004-06/2012) RWTH Aachen University: Studies in Industrial engineering specialized in mechanical engineering.

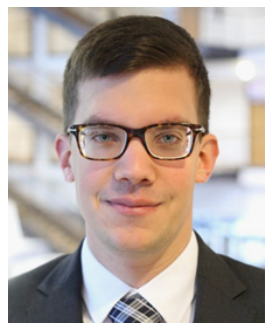

\section{Thomas Pullen}

RWTH Aachen University, Laboratory for Machine Tools and Production Engineering (WZL), Aachen, Germany t.pullen@wzl.rwth-aachen.de

(04/2014-now) Laboratory for Machine Tools and Production Engineering (WZL), RWTH Aachen University: Research Engineer, Cutting Technology Department; (06/2013-12/2013) Trinity College Dublin, Department of Mechanical and Manufacturing Engineering: 6-month stay for the experimental conduction of the master thesis; (04/2012-03/2014) RWTH Aachen University, Aachen: Production Technology, Master of Science. Thesis Topic: Development, Implementation and Review of Concepts for the Force Measurement in Broaching Using Passive SAW-Strain Sensors in Process Monitoring; (10/2007-03/2012) RWTH Aachen University, Aachen: Mechanical Engineering, Bachelor of Science. Field of specialisation: Production Technology. Thesis Topic: Investigation of the parameter influence for a calculation model to predict the temperature in the machining zone when broaching nickel-base alloys.

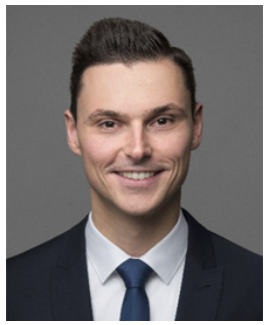

\section{Daniel Schraknepper}

RWTH Aachen University, Laboratory for Machine Tools and Production Engineering (WZL), Aachen, Germany d.Schraknepper@wzl.rwth-aachen.de

(01/2019-now) Laboratory for Machine Tools and Production Engineering (WZL), RWTH Aachen University: Head of Department for Cutting Technology; (01/2018-12/2018) Fraunhofer Institute for Production Technology (IPT), Aachen: Group Leader - Department for High Performance Cutting; (12/2012-12/2017) Fraunhofer Institute for Production Technology (IPT), Aachen: Research Assistant - Department for High Performance Cutting; (10/2006-11/2012) RWTH Aachen University, Aachen: Study of Mechanical Engineering, Dipl.-Ing.

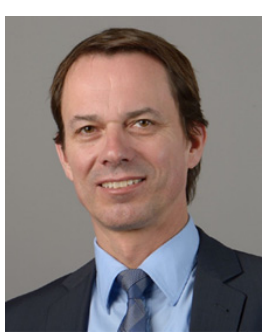

Prof. Dr.-Ing. Thomas Bergs RWTH Aachen University, Laboratory for Machine Tools and Production Engineering (WZL), Aachen, Germany t.bergs@wzl.rwth-aachen.de

(1967) born, december 21st, 1967; (1987) High school graduation; (1987-1988) Military Service - Gebirgsjagerbataillon, Bischofswiesen; (1988-1991) Basic Studies - Mechanical Engineering University Duisburg GH; (1991-1995) Main Studies - Mechanical 
Engineering - Rheinisch-Westfalischen Technischen Hochschule (RWTH) Aachen University; (1994-1995) Diplomar Thesis - Engineering Research Center for Netshape Manufacturing, ERC/NSM, Columbus, Ohio, USA; (1995-2000) Research Assistent - FraunhoferInstitute for Production Technology, Aachen; (2001) Doctorate at RWTH Aachen University; (2005-2019) Managing Partner Aixtooling GmbH; (2009-2011) Executive Master of Business Administration - MBA (RWTH); (2001-2018) Managing Chief Engineer at the Fraunhofer Institute for Production Technology IPT, Aachen; (since 01.06.2018) Head ofthe Chairof Manufacturing Process Technology at the Laboratory for Machine Tools and Production Engineering WZL of RWTH Aachen University.

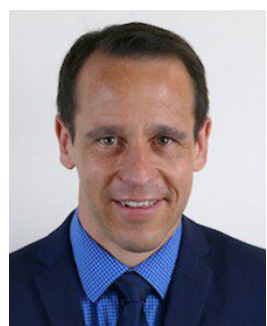

Univ.-Prof. Dr.-Ing. Sebastian Münstermann RWTH Aachen University, Integrity of Materials and Structures, Steel Institute (IEHK), Aachen, Germany

Sebastian.Muenstermann@iehk.rwthaachen.de 